\title{
Design principles for interdisciplinary collaborative learning through social, digital innovation
}

\section{Belinda Verster ${ }^{1}$, Carolien van den Berg ${ }^{2}$}

${ }^{1}$ Department of Town \& Regional Planning, Cape Peninsula University of Technology, Cape Town, South Africa, ${ }^{2}$ Department of Information Systems, University of the Western Cape, Cape Town, South Africa.

\begin{abstract}
As academics, we are acutely aware of our responsibility in the design of our teaching and learning environment to instil principles of ethics, sustainability, agency and social justice. We are at the crossroad between the commodification of knowledge versus learning that steeped in well-being and innovative socio-ecological and or socio-technical transitions. These complexities prompted a Design-Based Research (DBR) project that commenced in 2020 to test and refine design principles that can facilitate an interdisciplinary, collaborative learning environment that exposes students to future challenges foregrounded in social justice perspectives of local voice, collaboration and co-design. A conceptual model informed by four pedagogical propositions of relationality, reflexivity, responsiveness and recognition is stipulated and nine design principles derived from these propositions are proposed. The overall purpose of this DBR project is to situate the student within a multifaceted learning experience that mimics the complexities associated with an interdisciplinary collaborative learning environment steeped in contemporary societal problems within a specific societal context. The ultimate aim of this project is to shift from interdisciplinary to transdisciplinary collaboration to explore a holistic approach to complex societal problems.
\end{abstract}

Keywords: Design-based research; interdisciplinary learning; social digital innovation; interdisciplinary research. 


\section{Introduction}

Higher Education Institutions (HEI's) are at the crossroad between the commodification of knowledge on the one hand and learning that foregrounds well-being and innovative socioecological transitions on the other (Tassone et al., 2018). Such transitions require a broader perspective of complex challenges in society such as amplifying community voices while being socially, economically and environmentally responsible. In order for students to develop the ability to interpret and untangle complex, wicked problems, we argue and experiment with the value that multiple perspectives bring to the learning environment. Such an endeavour requires an interdisciplinary - and ultimately a transdisciplinary - design of learning environments to develop competencies and skills for ethical decision making.

In this paper, we propose pedagogical propositions and draft design principles for the design of a learning environment that facilitates social, digital innovation in an interdisciplinary, collaborative community. These findings stem from a Design-Based Research (DBR) project that commenced in 2020. The overall purpose of the DBR project is to situate the student within a complex learning experience that mimics the complexities associated with a transdisciplinary collaborative engagement with contemporary societal problems in the global South context.

We structure this paper by first providing an overview of the value that both social, digital innovation and interdisciplinary collaboration bring to creating a complex learning environment. We then contextualise DBR as a constructive methodology for this project. Next, we engage with literature and theory enriched pedagogical propositions to identify practical draft design principles and we conclude by plotting a way forward.

\section{Social, digital innovation as a catalyst for empowered communities}

As academics, we are acutely aware of our responsibility in the design of our teaching and learning environment to instil principles of ethics, sustainability, agency and social justice. We recognise the dual identity of students as both future professionals and responsible and responsive citizens. Our practice areas are Information Systems (IS) and Urban Planning (URP). In IS, students need to become aware of how technology can shape the future landscape and the implications thereof whilst URP planners are instrumental in design practices and their impact on society. We started considering how our students can learn from one another and how this will open up their perspectives. This resulted in a DBR project where we are busy collectively exploring the possibilities of social digital innovations within communities in Cape Town, South Africa.

Digital social innovation incorporates the use of digital technology in social innovations. We are looking at the potential thereof but want to view it primarily from the social and then find 
digital innovations to alleviate specific social problems within the students' own communities. As argued by Baek, Meroni \& Manzini (2015), the active engagement by a community in the collaborative production of solutions to their own social problems, creates a positive impact on society as a whole. By tapping into the lived and local knowledge of both students and their communities, we can focus on "the value of community resources or social capital" which represents the 'social' in social, digital innovation (van den Berg \& Verster, 2020).

\section{The value of interdisciplinary collaborative engagement}

Although interdisciplinary collaboration is a well-established approach, especially in the social sciences, its presence and thus impact on learning environments are limited. Holley (2009, p1) argues that the reason for the lack of uptake by HEI departments of interdisciplinary collaboration might be the "separate, often isolated department" structure that we find in universities plus the complexity of guiding "students to interact with faculty and areas of knowledge from multiple disciplines". Interdisciplinary collaboration, because of its layers of complexity, takes time as Dorst (2018) rightly comments that engaging with complexity cannot - and should not - be hurried.

Although interdisciplinary collaborative engagements may be complex, the benefits such as creative engagement with new knowledge, negotiating complex perspectives, developing critical thinking skills, participating in different and challenging ways of communicating, overshadows the challenges.

The motivation to embark on this DBR project was multifaceted, one aspect that we identified was shortcomings in the design process within our disciplines. From our experience, there is a tendency for IS students to design a solution without clearly understanding the bigger, systemic problems. On the other hand, urban planners are well known for their ability to unpack and understand a problem in fine detail, to the point of neglecting implementation. Interdisciplinary collaboration presents opportunities for project teams that apply an urban planning lens to uncover the complexity of problem-solving in collaboration with communities and other stakeholders in order to identify a solution that can be prototyped and potentially implemented. This can facilitate a combination of urbanisation, technology-led solutions.

To test our hypothesis during the first phase of the DBR project, a pilot project with a group of IS students was launched in 2020 see (van den Berg and Verster, 2020). The outcome of phase one was four pedagogical propositions namely Relationality, Reflexivity, Recognition and Responsiveness. 


\section{Methodology}

The four-phased DBR approach as defined by Reeves (2006) is applied to the project (see Figure 1). The first phase mandates collaboration between stakeholders such as researchers, practitioners and participants to improve teaching and learning practices.

\section{Design-Based Research}

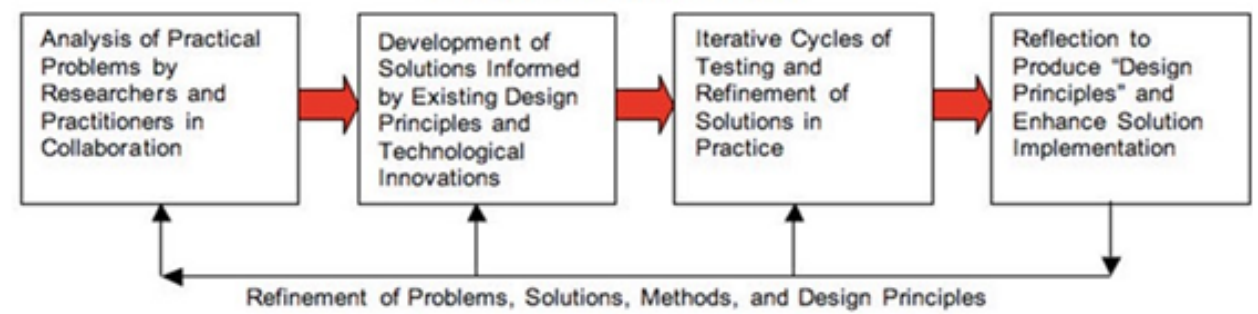

Figure 1. The four-phased DBR approach. Source: Reeves (2006)

The second phase of a DBR project builds on findings from the initial phase to develop draft design principles that are evaluated via a further review of relevant literature and theory. The outcome of this phase will be discussed in the following section.

\section{Four pedagogical propositions with draft design principles}

In this section we engage with literature and theory to enrich the pedagogical propositions in order to crystalise draft design principles. An important disclaimer to consider is that the four propositions are highly entangled and are all affected by each other. For example, when thinking with relationality, it is very difficult to remove it from recognition and its focus on acknowledging and comprehending human and non-human relationships. Sections 5.1 - 5.4 use a structure of first providing a short discussion of each enriched pedagogical proposition followed by its associated draft design principles.

\subsection{Pedagogical Proposition 1 - Relationality}

Students (as future designers) need to grasp the complexity of wicked problems that reside within the collective or societal sphere. These complexities can reside in the collective voice of a community and how communities depend on social relationships and relational structures to solve day-to-day and long-term problems. In this, it is important to harness the potential of interdisciplinary project teams to collectively dissect and position problem statements.

IS students need to approach interventions from a socio-technical perspective that incorporates aspects of the lived reality of people and how they interact within their community, whilst URP students need to engage with the implementation thereof. The design 
of a technical system has to be based on understanding the social system (Baek et al., 2015). This will foreground the opportunities presented by digital innovation with an emphasis on local knowledge and agency. We need to design a learning environment steeped in a framework that enables students' appreciation of culture and how this determines thoughts and actions with self and others.

Draft design principle 1: Anchor the project on the proposition of relationality through an emphasis on the social within social digital innovations. Implement a capstone project that comprises interdisciplinary student groups that are situated within the students' communities. Provide structure by stipulating a targeted problem area, for instance, those derived from the Sustainable Development Goals (SDGs).

Draft design principle 2: Create a blended learning environment by incorporating an eproject portfolio that showcases the different stages of the project from problem definition to the development of a digital innovation prototype. There should be evidence of deep engagement with the problem and the community voice. Include digital stories, representative personas and video clips in the e-portfolio.

\subsection{Pedagogical Proposition 2 - Reflexivity}

We draw on Schon's (1987) theory that stipulates two types of reflective/reflexive action, reflection-on-action where students reflect on past activities or actions, and reflection-inaction where there is a reflection on actions as they are being performed. We understand reflection-in-action as closely related to reflexivity with its focus not only on being retrospective but being a forward-looking instrument that allows for changing and adapting practices as students move through the stages of the project. Reflexivity is a powerful learning tool that creates spaces for disrupting established and traditional understandings and perceptions. It can also acknowledge the student's voice and thus raise the levels of empowerment and as such position the student in the centre of the learning environment.

The political Ethic of Care (EoC) framework (Tronto, 2013) provides a useful lens to sensitise students to the elements of care that are especially needed within a complex context such as interdisciplinary collaborative learning. Elements such as "attentiveness, responsibility, competence, responsiveness, trust and solidarity" specify the expectations to students.

Draft design principle 3: Develop a formal reflexive practice by structuring reflexive exercises such as individual blogs and reflexive questionnaires throughout the lifespan of the project. Do not assume students are naturally reflexive individuals and focus attention and specific activities on developing the reflexive ability. 
Draft design principle 4: Provide structure to what the expectations are of a student as part of a group/community of learning by introducing the EoC framework. Use the elements of this framework continuously during the project to monitor collaborative behaviours.

\subsection{Pedagogical Proposition 3 - Responsiveness}

Responsiveness acknowledges that change requires the collective intelligence of multiple stakeholders to identify systemic problems and that a collective, deep understanding of the problem is required (Tassone et al., 2018). Complex or wicked problems can only be interrogated once you have a grasp of the complexities and underlying nuances of the issues involved (Buchanan, 2019). The ability to respond to a problem/s by applying multiple lenses to dissect it requires reflexivity to situate the issue/problem. The duality of a deep understanding of a problem and further implementing a potential solution via social digital innovations are the core of our inquisition.

Draft design principle 5: Apply authentic assessment principles to design a creative and fluid assessment rubric to capture what is valued in this project. For example, levels of engagement and aspects about the giving and receiving of commentary and feedback (Boud \& Molloy, 2013).

Draft design principle 6: Include peer reviews in the face-to-face and online environment that encourages experimentation. Innovation requires one to be willing to fail and to try other options (Ries, 2011). Peers must be involved in the feedback process to open the conversation and allow an environment of mutual sharing and learning.

Draft design principle 7: Implement a design thinking method in the project rollout using the Stanford School of Design method of five phases (empathize, define, ideate, prototype and test) (Brown \& Wyatt, 2010).

\subsection{Pedagogical Proposition 4 - Recognition}

Recognition of context, in our case the global South and specifically South Africa. Here we are arguing for teaching and learning in the context of all the social ills and societal challenges that are not only part of daily life, but that our students would have to negotiate when entering the world of work (Fomunyam \& Teferra, 2017).

Recognition of multiple perspectives, we argue with Fomunyam \& Teferra (2017) that "plurality of voices provokes the creation of disciplinary and interdisciplinary spaces". A shift of the student from the outsider to the insider position, we argue, is thus possible through interdisciplinary collaborative learning.

A final aspect of recognition is engaging with the human and non-human relationship. This is especially relevant in a project where two disciplines have different focuses with regards to the centrality of the human (URP) and non-human (IS). 
Draft design principle 8: Include government and NGO stakeholders as critical soundboards for showcasing student project artefacts and plan implementation pilots. Student teams should have the opportunity to present their findings to a wider panel and the winning group needs to be linked to an innovation hub to showcase findings to a community of designers and innovators such as Silicon-Cape or Innovation hub Africa.

Draft design principle 9: Frame the student project within a theme that has contextual relevance by focussing on local communities and their lived experiences. By acknowledging the student as a local community member, we are recognising and capitalising on the prior local knowledge that students bring to the learning environment.

\section{Way Forward}

Two important objectives are set for the future of this DBR project:

First, is the rolling out of a larger scaled interdisciplinary collaborative student project to include a cohort of IS as well as URP honours students with the learning environment specifically developed with the four pedagogical propositions and associated draft design principles, as developed in this paper, in mind. The design principles need to be tested and refined following an iterative process as defined in the third phase of DBR. We are planning three iterations between 2021 and 2022 .

The second objective is to shift from interdisciplinary to transdisciplinary collaboration. The reason for this intentional shift is to capitalise on the value that a transdisciplinary position provides by transcending disciplinary knowledge into an innovative holistic approach to complex, wicked problems. In the global South context with its limited access to capital resources, following a transdisciplinary approach could result in more sustainable solutions.

In conclusion, the pedagogical propositions and associated draft design principles as developed in this paper should be considered as entry points to the highly complex and entangled real world challenges our students need to negotiate as young emerging professionals. 


\section{References}

Baek, J. S., Meroni, A., \& Manzini, E. (2015). A socio-technical approach to design for community resilience: A framework for analysis and design goal forming. Design Studies, 40, 60-84.

Boud, D., \& Molloy, E. (2013). "Rethinking Models of Feedback for Learning: The Challenge of Design." Assessment and Evaluation in Higher Education 38(6), 698-712.

Brown, T. \& Wyatt, J. (2010). Design thinking for social innovation IDEO. Development Outreach. 12(1), pp. 29-31.

Buchanan, R. (2019). "Systems Thinking and Design Thinking: The Search for Principles in the World We Are Making." She Ji 5(2), 85-104.

Dorst, K. (2018). Mixing Practices to Create Transdisciplinary Innovation: A Design-Based Approach. Technology Innovation Management Review, 8(8), 60-65.

Fomunyam, K. G., \& Teferra, D. (2017). Curriculum responsiveness within the context of decolonisation in South African higher education. Yesterday and Today, 17, 38-63.

Holley, K. A. (2009). Understanding Interdisciplinary Challenges and Opportunities in Higher Education. ASHE Higher Education Report, 35(2), 1-131.

Schön, D. A. (1987). Educating the reflective practitioner: Toward a new design for teaching and learning in the professions. Jossey-Bass.

Reeves, T. C. (2006). Design research from the technology perspective. In J. V. Akker, K. Gravemeijer, S. E. McKenney, \& N. Nieveen (Eds.), Educational Design Research (pp. 86-109). London: Routledge.

Ries, E. (2011). The Lean Startup. 1st ed. Crown Business.

Tassone, V. C., O’Mahony, C., McKenna, E., Eppink, H. J., \& Wals, A. E. J. (2018). Redesigning higher education curricula in times of systemic dysfunction: a responsible research and innovation perspective. Higher Education, 76(2), 337-352.

Tronto, J.C. (2013). Caring Democracy: Markets, Equality, and Justice. New York: New York University Press.

Van den Berg, C \& Verster, B (2020), September. Co-Creating Social, Digital Innovation to Recognise Agency in Communities: A Learning Intervention. 2020 South African Institute for Computer Scientists and Information Technologists (SAICSIT) conference. 14-16 September 2020. 